\title{
EDUCAÇÃO, TRABALHO E CIDADANIA a educação brasileira e o desafio da formação humana no atual cenário histórico
}

\author{
Antônio J. Severino \\ Professor de Filosofia da Educação da Faculdade de Educação da USP
}

\begin{abstract}
Resumo: O texto desenvolve uma reflexão filosófico-educacional sobre a condição da educação como prática mediadora da existência histórica dos homens, explicitando seus desafios e compromissos diante da sua situação concreta no contexto social brasileiro da atualidade.

Palavras-chave: educação e sociedade; educação e trabalho; educação e realidade brasileira.
\end{abstract}

$\mathrm{A}$ humanidade vive, hoje, um momento de sua história marcado por grandes transformações, decorrentes sobretudo do avanço tecnológico, nas diversas esferas de sua existência: na produção econômica dos bens naturais; nas relações políticas da vida social; e na construção cultural. Esta nova condição exige um redimensionamento de todas as práticas mediadoras de sua realidade histórica, quais sejam, o trabalho, a sociabilidade e a cultura simbólica. Espera-se, pois, da educação, como mediação dessas práticas, que se torne, para enfrentar o grande desafio do $3^{\circ}$ milênio, investimento sistemático nas forças construtivas dessas práticas, de modo a contribuir mais eficazmente na construção da cidadania, tornando-se fundamentalmente educação do homem social.

A educação, como processo pedagógico sistematizado de intervenção na dinâmica da vida social, é considerada hoje objeto priorizado de estudos científicos com vistas à definição de políticas estratégicas para o desenvolvimento integral das sociedades. Ela é entendida como mediação básica da vida social de todas as comunidades humanas. Esta reavaliação, que levou à sua revalorização, não pode, no entanto, fundar-se apenas na sua operacionalidade para a eficácia funcional do sistema socioeconômico, como muitas vezes tendem a vê-la as organizações oficiais, grandes economistas e outros especialistas que focam a questão sob a perspectiva da teoria do capital humano.
Sem dúvida, a existência real dos homens é profundamente marcada pelos aspectos econômicos, até porque esta dimensão econômica, devidamente entendida, constitui mesmo uma referência condicionante para as outras dimensões da vida humana, uma vez que ela se liga à própria sobrevivência da vida material.

Porém, a significação dos processos sociais e, no seu âmbito, dos processos educacionais não se restringe a essa sua funcionalidade operatória. Se, de um lado, é a realidade dos fatos que permite que a educação tenha alguma incidência social, de outro, essa eficácia só ganha legitimidade humana se se referir a significações que ultrapassem sua mera facticidade e seu desempenho operacional. Buscar explicitar esses valores e significações é o que cabe a uma abordagem filosófica da educação e tal é o objetivo deste texto, ainda que nos restritos limites de espaço de que dispõe.

Refletir filosoficamente sobre a educação não é dispensar os dados e análises que as ciências especializadas podem trazer e fazer; ao contrário, uma abordagem filosófico-educacional precisa levar em consideração esse retrato de corpo inteiro que a ciência faz da educação nos dias de hoje. O pensar filosófico não parte de referências abstratas e idealizadas, aprioristicamente colocadas, mas sim da própria realidade de seu objeto. Assim ela toma em conta as conclusões das ciências, procurando clarear os objetivos e finalidades que precisam ser selecionados e privile- 
giados, até mesmo na definição dos meios, para que elas possam subsidiar as políticas sociais. É neste plano das finalidades que se estabelece o diálogo entre as perspectivas científica, filosófica e política, sendo esta última perspectiva entendida como o planejamento e a execução de ações que interferem diretamente na dinâmica social.

Portanto, o objetivo do presente texto é aduzir algumas considerações sobre a significação da educação, como mediação concreta da existência real da sociedade brasileira, no quadrante histórico atual. Para tanto, parte de uma configuração da situação em que se encontram as relações entre educação e sociedade, desenvolvendo em seguida considerações sobre o necessário redimensionamento de seu papel, em face das exigências postas pela significação da condição humana, fundada na iminente dignidade dos seres humanos como pessoas.

\section{A NOVA ORDEM MUNDIAL: A PROMESSA}

De acordo com um senso comum atualizado, vigente nos meios acadêmicos, nos meios de comunicação e até mesmo nos meios populares, estaríamos vivendo hoje um mundo totalmente diferente daquele projetado pela visão iluminista da modernidade, constituindo uma nova ordem mundial. Estaríamos vivendo um momento de plena revolução tecnológica, capaz de lidar com a produção e transmissão de informações em extraordinária velocidade, num processo de globalização não só da cultura, mas também da economia e da política. Tratar-se-ia de um momento marcado pelo privilegiamento da iniciativa privada, pela minimalização da ingerência do Estado nos negócios humanos, pela maximalização das leis do mercado, pela ruptura de todas as fronteiras. Tal situação leva Octavio Ianni (1998:28) a afirmar que "o que está em causa é a busca de maior e crescente produtividade, competitividade e lucratividade, tendo em conta mercados nacionais, regionais e mundiais. Daí a impressão de que o mundo se transforma no território de uma vasta e complexa fábrica global e, ao mesmo tempo, em shopping center global e disneylândia global".

No plano mais especificamente filosófico, estaria em pauta uma crítica cerrada às formas de expressão da razão teórica da modernidade, propondo-se a desconstrução de todos os discursos por ela produzidos, todos colocados sob suspeita, até mesmo aqueles da própria ciência. Todos os grandes sistemas teóricos interpretativos da realidade humana são caracterizados como metanarrativas e, como tal, desconsiderados. Já teríamos entrado então em plena pós-modernidade. ${ }^{1}$
No entanto, este modo de ver e existir atuais, de perfil assumidamente neoliberal, com suas decorrências e expressões no plano cultural, com sua exacerbação do individualismo, do produtivismo, do consumismo, da indústria cultural, da mercadorização até mesmo dos bens simbólicos, não instaura nenhuma pós-modernidade. Com efeito, o que está de fato acontecendo é a plena maturação das premissas e promessas da própria modernidade. Nada mais moderno do que esta expansão e consolidação do capitalismo, envolvido numa aura ideológica de liberalismo extremado; nada mais moderno do que esta tecnicização, viabilizada pela revolução informacional. Finalmente, a modernidade está realizando as promessas embutidas em seu projeto civilizatório. Nada mais moderno do que o individualismo egoísta dos dias de hoje. No fundo, é a mesma racionalidade que continua dirigindo os rumos da história humana, em que pesem as críticas que são feitas à sua forma de expressão até o século 19.

Que tal situação configure um contexto novo, não há como negar nem recusar. E que obviamente exige reequacionamentos por parte de todos nós, quaisquer que sejam os lugares que ocupemos na dinâmica sociocultural. Isso não está em questão. Porém, o que cabe aqui é uma rigorosa atenção a essa especificidade do momento histórico, não se deixando levar nem por uma atitude de mera anatematização moralizante ou saudosista, nem por um deslumbramento alienante. Análise detida e vigilância crítica, isto é o que se impõe.

Da mesma forma, é preciso não perder de vista a historicidade da existência humana, não se deixando iludir pela idéia de que o fim das utopias do progresso humano possa significar igualmente o fim da história. Portanto, deve-se ter bem presente que a atual situação possui também uma configuração histórica.

Além disso, é necessário considerar a dura realidade do contexto histórico latino-americano, em que as marcas da exclusão humana continuam com presença muito forte. A gravidade da situação desmente qualquer veleidade de que já se teria encontrado o caminho certo para a construção de uma sociedade amadurecida, justa e democrática. $\mathrm{O}$ processo de modernização pelo qual passou e continua passando o continente está acontecendo a um preço muito alto. A organização econômica, de lastro capitalista, sob um clima político de mandonismo interno das elites nacionais e da dominação externa dos grupos internacionais, impõe uma configuração socioeconômica na qual as condições de vida da imensa maioria da população continuam extremamente precárias. $\mathrm{Na}$ verdade, o aclamado proces- 
so de globalização da economia parece universalizar as vantagens do capital produtivo e as desvantagens do trabalho assalariado. Dada essa situação, o conhecimento, em geral, e a educação, em particular, são interpelados com relação a seu papel histórico.

A América Latina vem sendo considerada, por todos os especialistas, a região do planeta que apresenta as maiores desiguadades, que ademais são submetidas a intensos processos de piora contínua. Aqui está ocorrendo um "excesso de pobreza", responsável pela magnitude e profundidade dos impactos negativos decorrentes da situação (Kliksberg, 2000:14).

\section{DESORDEM E FRUSTRAÇÃO DA PROMESSA}

Entretanto, qual a realidade histórico-social encontrada no Brasil, neste atual momento? Como andam essas mediações nas quais cabe a educação investir? Segundo o Relatório das Nações Unidas, com a avaliação do IDH - Índice de Desenvolvimento Humano -, recém-lançado, o Brasil regride para o rol dos países de desenvolvimento médio, passando a ocupar o $79^{\circ}$ lugar entre 174 países avaliados. Parece até uma boa colocação, não fosse o fato de que essa posição não decorre da carência de recursos objetivos. Se estes fossem levados em conta, o país precisaria estar colocado entre os 30 primeiros países do planeta. O trágico é que esta posição representa termos de selvageria na distribuição dos bens materiais e culturais de que o país dispõe, provocando um grave nível de desumanização.

Com efeito, o país está com uma das mais altas concentrações de renda do mundo, medida pelo índice de Gini e que se expressa da seguinte maneira: enquanto os $20 \%$ mais pobres precisam distribuir entre si apenas $2,5 \%$ da renda do país, os $20 \%$ mais ricos se locupletam com $63,4 \%$, ou seja, no Brasil, 30 milhões de pessoas precisam sobreviver com a pequena fatia de $2,5 \%$ e outros 30 milhões dispõem de $63,4 \%$ para o mesmo fim. O PIB anual per capita dos $20 \%$ mais ricos é de US\$18.563,00, enquanto o dos $20 \%$ mais pobres é de apenas US $\$ 578,00$, portanto, 32 vezes menor. Embora o país tenha enriquecido nos últimos anos, não conseguiu transformar esta riqueza em maior expectativa de vida e em educação. ${ }^{2}$

Esta situação particular do Brasil é pior do que a do conjunto da América Latina, que já é péssima: os $20 \%$ mais ricos dispõem de $52,94 \%$ da renda e os $20 \%$ mais pobres, de 4,52\%. Na África do Norte e no Oriente Médio, essa correlação é 45,35\% e 6,90\% (Kliksberg, 2000:34).
O retrato da existência real da população brasileira é o seguinte: 17\% vivem na miséria, ou seja, 26 milhões de pessoas; 17.600 .000 de pessoas morrem antes de atingir os 40 anos; 24.480 .000 são analfabetos; 36.720 .000 não contam com água potável; e 45.900 .000 não dispõem de esgoto.

No caso das condições das mulheres, medidas pelo IDH, verificou-se ligeira melhora do desempenho do país, mas, como observa o jornal $O$ Estado de S. Paulo (11/07/99), "isso ocorre mais pelos problemas dos outros países do que pelas virtudes brasileiras". O Brasil ocupa o 67ㅇ lugar, devido sobretudo à longevidade feminina. A expectativa de vida das mulheres é de 71 anos, ao passo que a dos homens é de 63 anos. Na educação, pequena vantagem para os homens: alfabetização e matrícula de meninos correspondem a, respectivamente, $84,1 \%$ e $82 \%$ contra $83,9 \%$ e $77 \%$ para as meninas. No entanto, na renda, o PIB per capita refaz a diferença: o homem leva $\mathrm{R} \$ 9.035,00$ contra $\mathrm{R} \$ 3.863,00$ das mulheres, portanto, uma diferença de 2,4 vezes, lembrando-se que a diferença média mundial é de apenas $1,8 \mathrm{vez}$. No exercício do poder institucionalizado, a situação das mulheres torna a cair, arrastando o Brasil para o $70^{\circ}$ lugar entre 102 países: só 5,9\% das vagas parlamentares e $17,3 \%$ dos cargos diretivos cabem às mulheres.

Apesar de ter índice de $100 \%$ de imunização contra a tuberculose, em 1997, o país registrou 54 casos da doença por 100 mil habitantes. A média dos países desenvolvidos é de 19,6 casos.

A mortalidade infantil, no Brasil, atinge 37 casos por mil nascimentos; as mortes de crianças até 5 anos sobem para 44 casos por mil nascimentos. A mortalidade materna alcança 220 casos por cem mil partos. Os médicos, no país, são 134 por cem mil habitantes.

No Relatório Progresso das Nações 1999, publicado pela Unicef, o Brasil ocupa o $102^{\circ}$ lugar no ranking de risco para a infância, entre 142 países pesquisados ( $\mathrm{Fo}$ lha de S.Paulo, 23/07/99). Para essa classificação, foram levados em conta o índice de mortalidade infantil, o índice de amamentação integral e o índice de crianças fora da escola.

Por outro lado, é alta a incidência de trabalho escravo no país. De 1966 a 1996, foram constatados 21.826 trabalhadores escravizados (Folha de S.Paulo, 05/07/99).

Já de acordo com a PNAD, de 1995, das crianças em idade de 7 a 14 anos, $3 \%$ só trabalham e 6,8\% não trabalham mas também não estudam, o que corresponde a cerca de 2.800 .000 crianças fora de qualquer ambiente formal de estudo; e 10,5\% estudam e trabalham simultaneamente, o que deixa, em 1995, 79,7\% da população desta faixa etária ape- 
nas estudando, atendida pelos serviços da educação, ainda que de forma muitas vezes precária.

Atualmente, embora tenham melhorado esses índices de desempenho da educação nacional, tanto no ensino médio como no fundamental, uma vez que, entre $1996 \mathrm{e}$ 1997, diminuíram os índices de retenção e de evasão no sistema, os níveis ainda são muito altos. A taxa de promoção no ensino fundamental, em 1997, foi de $77,5 \%$ e a de evasão, $11,1 \%$. No ensino médio, estas taxas correspondem, respectivamente, a 78,8\% e $13 \%$. O país continua com $16 \%$ de analfabetos, ou seja, 24.480 .000 pessoas.

Outro aspecto que merece atenção diz respeito à situação dos professores. Segundo o MEC, o país tem 1.380.000 professores, dos quais 779.000 não possuem curso superior; destes, 124.000 não concluíram o nível médio e 63.700 nem mesmo o ensino fundamental. Dos cerca de $600 \mathrm{mil}$ com ensino superior, 81 mil têm licenciatura incompleta e quase 23.000 bacharéis lecionam mas não têm formação pedagógica. Este quadro mostra que uma grande massa de professores não possui formação específica para o magistério. Mostra também como o trabalho está degradante; como a sociabilidade está deteriorada e opressiva; como a cultura está alienante e precariamente dividida; como andam as mediações da existência humana no Brasil, acenando para os desafios que a educação brasileira precisa enfrentar para cumprir sua missão intrínseca que é a de investir nas forças construtivas das práticas relacionadas ao trabalho, à vida social e à cultura simbólica.

O que se constata, no entanto, com relação à educação brasileira, é que ela está significativamente deficitária. Como se viu, o déficit educacional expressa-se em números muito elevados. Tal situação cobra de todos os brasileiros sensíveis ao valor da dignidade da pessoa humana, e portanto de sua postura ética, o seu decisivo compromisso de estar fazendo com que sua prática político-educativa se transforme em investimento competente na consolidação das condições de trabalho, na construção da cidadania (no plano das pessoas) e da democracia (no plano da sociedade) e na expansão da cultura simbólica, utilizando-se de todos os recursos disponíveis, de modo especial, a ferramenta do conhecimento.

\section{EDUCAÇÃO E FORMAÇÃO DO HOMEM SOCIAL}

Ao contrário do que sempre alegaram a metafísica tradicional e a ciência moderna, todas as formas de manifestação concreta da existência humana se realizam mediante a ação real, o agir prático. Com efeito, a substância do existir é a prá- tica. Só se é algo mediante um contínuo processo de agir, só se é algo mediante a ação. Assim, diferentemente do que pensavam os metafísicos clássicos, não é o agir que decorre do ser, mas é o modo de ser que decorre do agir. É a ação que delineia, circunscreve e determina a essência dos homens. É na e pela prática que as coisas humanas efetivamente acontecem, que a história se faz.

Este é o sentido da historicidade da existência humana, ou seja, os homens não são a mera expressão de uma essência metafísica predeterminada, nem a mera resultante de um processo de transformações naturais que estariam em evolução. Ao contrário, naquilo em que são especificamente humanos, eles são seres em permanente processo de construção. Nunca estão prontos e acabados, nem no plano individual, nem no plano coletivo, como espécie. Por sobre um lastro de uma natureza físico-biológica prévia, mas que é pré-humana, compartilhada com todos os demais seres vivos, eles vão se transformando e se reconstruindo como seres especificamente humanos, como seres "culturais". E isso não apenas na linha de um necessário aprimoramento, de um aperfeiçoamento contínuo ou de progresso: ao contrário, estas mudanças transformativas, decorrentes de sua prática, podem ser regressivas, nem sempre sinalizando para uma eventual direção de aprimoramento de nosso modo de ser. O que é importante observar é que os seres humanos vão sendo aquilo que se vão fazendo e este fazer-se, este constituirse só se dá mediante a ação e não pelos seus desejos, pelos seus pensamentos e teorias.

Assim, a educação não poderá mais ser vista como processo mecânico de desenvolvimento de potencialidades. Ela será necessariamente um processo de construção, ou seja, uma prática mediante a qual os homens estão se construindo ao longo do tempo.

\section{Conservação e Reposição da Existência pelo Trabalho}

Porém, quando se analisa a realidade humana em sua historicidade, percebe-se logo que a esfera básica da existência humana prática e histórica dos homens é aquela do trabalho propriamente dito, ou seja, prática que alicerça e conserva a existência material dos homens, já que a vida depende radicalmente dessa troca entre o organismo e a natureza física.

Trabalho é entendido aqui não como mera operação técnica sobre a natureza, mas como a densa relação dos homens com ela. Daí a sua caracterização como a esfera produtiva, a esfera da prática econômica, mediante a qual 
os homens podem prover a conservação de sua existência física.

Como bem o mostram as ciências econômicas, o processo produtivo, de bens naturais e do próprio sujeito produtor, envolve, obviamente, não só o investimento da energia dos organismos humanos. Está implicada nesse processo a apropriação pelos homens dos recursos da terra, bem como dos meios tecnológicos da produção. Por isso, estão em pauta a saúde corporal das pessoas, a disposição de alimentos, de habitação, as formas e valores de remuneração do trabalho, enfim, as condições objetivas da produção, que são igualmente as fontes objetivas da existência real. Estas condições precisam estar equitativamente distribuídas, pois a desigualdade dessa distribuição é que resulta na pobreza, na doença, no desemprego, na baixa qualidade de vida, na privação também dos bens sociais e culturais.

Assim, de um primeiro ângulo, os homens estabelecem relações com a natureza material, da qual recebem seu organismo físico-biológico e da qual retiram, direta ou indiretamente, todos os elementos e recursos para a manutenção de sua existência material e para sua sobrevivência, tanto como indivíduos quanto como espécie. $\mathrm{O}$ conjunto das atividades desenvolvidas no âmbito destas relações constitui o universo do trabalho, a esfera da produção técnica e econômica.

\section{Organização da Sociedade para a Construção da Cidadania}

Entretanto, a prática produtiva dos homens não se dá como trabalho individual: ela é, antropologicamente falando, expressão necessária de um sujeito coletivo, ou seja, a espécie humana só é humana à medida que se efetiva em sociedade. Não se é propriamente humano fora de um tecido social, que constitui o solo de todas as relações sociais, não apenas como referência circunstancial, mas como matriz, placenta que nutre toda e qualquer atividade posta pelos sujeitos individuais. Porém, é preciso observar que essa trama de relações sociais que tece a existência real dos homens não se caracteriza apenas como coletividade gregária dos indivíduos, como ocorre nas "sociedades" animais: um elemento específico interfere aqui, mais uma vez marcando uma peculiaridade humana: a sociedade humana é atravessada e impregnada por um coeficiente de poder, ou seja, os sujeitos individuais não se justapõem, uns ao lado dos outros, em condições de simétrica igualdade, mas se colocam hierarquicamente, uns sobre os outros, uns dominando os outros. Torna-se assim uma sociedade política, uma cidade. Este coeficiente que marca as nossas relações sociais como relações políticas e que caracteriza nossa prática social envolve os indivíduos na esfera do poder.

Deste ponto de vista, uma estrutura social na qual o poder seja mais equitativamente distribuído é condição básica para que os homens se humanizem. É condição mínima para que haja cidadania. É neste sentido que se implicam as situações de democracia e de cidadania. É por isso que, no sentido mais restrito, cidadania se reporta ao gozo dos direitos políticos e sociais, embora não se limitando a eles, num sentido mais amplo.

A prática política responsável pela constituição histórica do existir humano se dá mediante o exercício das relações sociais, modalidade de intercâmbio entre pessoas: mas estas relações se humanizam na relação direta da minimização da dominação e na razão inversa da maximalização da opressão de uns sobre os outros. Trata-se de garantir para todos a participação nas tomadas de decisão sobre o destino do todo social, ainda que a partir de núcleos específicos em que este todo se realiza parcialmente.

\section{Educação e Instauração da Cultura Simbólica}

Porém, se a prática econômica e política são prioritárias e fundamentais na configuração do modo de existir humano, é necessário considerar que o agir humano tem suas especificidades, não se reduzindo nem ao determinismo onto-essencialista da metafísica, nem ao mecanicismo naturalista da ciência, nem ao seu decorrente pragmatismo funcionalista. A prática tipicamente humana, que delineia seu modo de ser, não é a prática mecânica, transitiva; ao contrário, é uma prática intencionalizada, marcada desde suas origens pela simbolização. É que, instaurando-se como prolongamento das forças energéticas instintivas, a subjetividade constitui-se como um novo equipamento, próprio da nova espécie, transformando-se num instrumento de ação dos homens.

Vai ocorrer então que tanto a prática produtiva quanto a prática política só se tornam práticas humanas porque são atravessadas por uma terceira dimensão específica do agir humano: trata-se da simbolização, da prática simbolizadora. Com efeito, a atividade técnica de transformação da natureza só se torna viável à medida que os homens, graças a seu equipamento de subjetividade, são capazes de duplicar simbolicamente os objetos de sua experiência, lidando com eles para além de sua imediatez. 
Esse contexto, como que um tecido que vai se complexificando pela contínua articulação de novas experiências, já tornadas possíveis pelas experiências passadas e acumuladas, é a cultura uma das mediações concretas da existência dos homens. E a cultura é o universo do saber. Isto é válido tanto no plano da experiência epistêmica do indivíduo - trata-se sempre de uma experiência que vai se construindo, acumulando, sintetizando, reorganizando, sistematizando dados - quanto no plano da própria humanidade, tanto na perspectiva ontogenética como na perspectiva filogenética.

\section{EDUCAÇÃO COMO MEDIADORA DA EXISTÊNCIA HISTÓRICA}

Pode-se então equacionar a existência humana como se dando mediada pelo tríplice universo do trabalho, da sociedade e da cultura. Como os três ângulos de um triângulo, esses três universos se complementam e se implicam mutuamente, um dependendo do outro, a partir de sua própria especificidade.

É nesse contexto que se pode entender as relações do conhecimento com o universo social. Com efeito, o conhecimento pressupõe um solo de relações sociais, não apenas como referência circunstancial, mas como matriz, como placenta que nutre todo seu processamento. Entretanto, essa trama de relações sociais em que se tece a existência real dos homens, como se viu antes, não se caracteriza apenas pelas relações de gregaridade dos indivíduos, tal qual ocorre nas "sociedades" animais, mas sobretudo por relações de hierarquização, envolvendo o elemento específico a interferir no social humano, o poder, que torna política a sociedade.

O saber aparece, portanto, como instrumento para o fazer técnico-produtivo, como mediação do poder e como ferramenta da própria criação dos símbolos, voltando-se sobre si mesmo, ou seja, é sempre um processo de intencionalização. Assim, é graças a essa intencionalização que nossa atividade técnica deixa de ser mecânica e passa a se dar em função de uma projetividade, o trabalho ganhando um sentido. Do mesmo modo, a atividade propriamente política se ideologiza e a atividade cultural transfigura a utilidade pragmática imediata de todas as coisas.

Como entender então a educação nesse contexto das mediações histórico-sociais que efetivamente manifestam e concretizam a existência humana na realidade? Ela deve ser entendida como prática simultaneamente técnica e política, atravessada por uma intencionalidade teórica, fecundada pela significação simbólica, mediando a integração dos sujeitos educandos nesse tríplice universo das mediações existenciais: no universo do trabalho, da produção material, das relações econômicas; no universo das mediações institucionais da vida social, lugar das relações políticas, esfera do poder; no universo da cultura simbólica, lugar da experiência da identidade subjetiva, esfera das relações intencionais. A educação só se legitima intencionalizando a prática histórica dos homens.

Com efeito, se se espera, acertadamente, que a educação seja de fato um processo de humanização, é preciso que ela se torne mediação que viabilize, que invista na construção dessas mediações mais básicas, contribuindo para que elas se efetivem em suas condições objetivas reais. Ora, esse processo não é automático, não é decorrência mecânica da vida da espécie. É verdade que, ao superar a transitividade do instinto e com ela a univocidade das respostas às situações, a espécie humana ganha em flexibilidade, mas, ao mesmo tempo, torna-se vítima fácil das forças alienantes, uma vez que todas as mediações são ambivalentes: constituem, simultaneamente, o lugar da personalização, e o lugar da desumanização, da despersonalização. Assim, a vida individual, a vida em sociedade, o trabalho, as formas culturais e as vivências subjetivas podem estar levando não a uma forma mais adequada de existência, da perspectiva humana, mas antes a formas de despersonalização individual e coletiva, ao império da alienação. Sempre é bom não perder de vista que o trabalho pode degradar o homem, a vida social pode oprimi-lo e a cultura pode aliená-lo, ideologizando-o.

Daí se esperar da educação que ela se constitua, em sua efetividade prática, um decidido investimento na consolidação das forças construtivas dessas mediações. É por isso que, ao lado do investimento na transmissão aos educandos, dos conhecimentos científicos e técnicos, impõese garantir que a educação seja mediação da percepção das relações situacionais, que ela lhes possibilite a apreensão das intrincadas redes políticas da realidade social, pois só a partir daí poderão se dar conta também do significado de suas atividades técnicas e culturais. Por outro lado, cabe ainda à educação, no plano da intencionalidade da consciência, desvendar os mascaramentos ideológicos de sua própria atividade, evitando assim que se instaure como mera força de reprodução social e se torne força de transformação da sociedade, contribuindo para extirpar do tecido desta todos os focos da alienação. 


\section{CONCLUSÃO}

O quadro da realidade social e educacional do Brasil mostra bem o quanto a existência histórica dos brasileiros está longe de atingir um patamar mínimo de qualidade. Mostra também o quanto é ainda grave o déficit educacional em termos quantitativos e qualitativos e como é ainda grande o desafio para os gestores da educação no Brasil. Exigem-se deles uma avaliação mais crítica da situação real da nossa sociedade e uma maior vigilância diante do mavioso canto das sereias do neoliberalismo.

Sem dúvida, a educação não é a alavanca da transformação social. No caso da sociedade brasileira, ainda sob o império da formação econômica capitalista, o núcleo substantivo de todas as relações sociais é a relação produtiva. Porém, a educação, como também outras formas de ação sociocultural, está diretamente relacionada com as condições da economia. É por isso que Gramsci (1976:9) sempre insistiu que nenhuma reforma intelectual e moral pode estar desligada da reforma econômica. Porém, se, por um lado, a educação pode contribuir para disfarçar, legitimando-as ideologicamente, e abrandar as contradições e os conflitos reais que acontecem no processo social, por outro, pode também desmascarar e aguçar a consciência dessas contradições, contribuindo para sua superação no plano da realidade objetiva. Se a educação pode ser, como querem as teorias reprodutivistas, um elemento fundamental na reprodução de determinado sistema social, ela pode ser também elemento gerador de novas formas de concepções de mundo capazes de se contraporem à concepção de mundo dominante em determinado contexto sociocultural (Severino, 1986:96).

\section{NOTAS}

E-mail do autor: ajsev@uol.com.br

1. Esta nova condição e suas conseqüências econômicas, sociais e políticas estão bem caracterizadas e analisadas em diversos artigos publicados no volume
12 da revista São Paulo em Perspectiva, números 2 e 3, de 1998. Trata-se de volume dedicado ao capitalismo atual, esclarecendo a situação do Brasil no contexto mundial. "No interior da internacionalização econômica, são apresentadas e discutidas as repercussões do processo de globalização, o significado da ideologia neoliberal e os efeitos das reformas políticas para alguns países da América Latina (...)", situando "de forma geral a economia brasileira em face das novas características da economia internacional" (São Paulo em Perspectiva, v.12, n.3, 1998:1).

2. O coeficiente de Gini é a medida dos graus de desigualdade na distribuição da renda. Ele é igual a 0 quando a eqüidade é máxima, a renda sendo eqüitativamente distribuída entre todas as pessoas que integram uma população. Vai de 0 a 1 . Países altamente eqüitativos, como Suécia e Espanha, têm o índice de Gini entre 0,25 a 0,30. A média mundial é 0,40 . A média da América Latina é de 0,57, enquanto o Brasil está com 0,69, após ter passado de 0,59 em 1980, para 0,63 em 1989 , o que mostra a continuidade do agravamento da concentração de renda nas últimas décadas (Kliksberg, 2000:84).

\section{REFERÊNCIAS BIBLIOGRÁFICAS}

ALTHUSSER, L. Ideologia e aparelhos ideológicos do Estado. São Paulo, Martins Fontes, s/d.

BELluZO, L.G. "Fim de século". São Paulo em Perspectiva. São Paulo, Fundação Seade, v.12, n.2, abr./jun. 1992, p.21-26.

FERREIRA, N.T. Cidadania: uma questão para a educação. Rio de Janeiro, Nova Fronteira, 1993

FRIGOTTO, G. A produtividade da escola improdutiva. São Paulo, Cortez/Autores Associados, 1984

GRAMSCI, A. Os intelectuais e a organização da cultura. Rio de Janeiro, Civilização Brasileira, 1968.

Maquiavel, a política e o estado moderno. 2a ed. Rio de Janeiro, Civilização Brasileira, 1976.

IANNI, O. "Globalização e neoliberalismo". São Paulo em Perspectiva. São Paulo, Fundação Seade, v.12, n.2, abr./jun. 1998, p.27-32.

KLIKSBERG, B. Desigualdade na América Latina: o debate adiado. São Paulo, Cortez/Unesco, 2000. Cortez, 1998

MARX, K. e ENGELS, F. A ideologia alemã. Lisboa, Presença, v.2, 1976.

ORTIZ, R. Mundialização e cultura. São Paulo, Brasiliense, 1994.

RODRIGUES, N. Estado, educação e desenvolvimento econômico. São Paulo, Cortez/Autores Associados, 1982.

SEVERINO, A.J. Educação, ideologia e contra-ideologia. São Paulo, EPU, 1986. Aprender) Filosofia da educação. São Paulo, FTD, 1994 (Col. Ensinar \&

. "A escola e a construção da cidadania". Sociedade civil e educação. Campinas, Papirus, 1992, p.9-14 (Coletânea CBE).

"A formação profissional do educador: pressupostos filosóficos e implicações curriculares". Revista da Ande, n.17, jun. 1991, p.29-40.

SINGER, P. "Para além do neoliberalismo: a saga do capitalismo contemporâneo”. São Paulo em Perspectiva. São Paulo, Fundação Seade, v.12, n.2, abr./jun. 1992, p.3-20. 